\title{
Research on the Equilibrium of a Revenue Sharing Contract in a Transfer-Operation-Transfer Project Based on the Theory of Share Tenancy
}

\author{
Yanhua Du1,2*, Jun Fang1, Jun Hu1 \\ ${ }^{1}$ School of Civil Engineering and Architecture, Wuhan University of Technology, Wuhan, China \\ ${ }^{2}$ School of Civil Engineering and Architecture, Zhengzhou University of Aeronautics, Zhengzhou, China \\ Email: ^duyh@zua.edu.cn, whutfj@126.com,1726958387@qq.com
}

How to cite this paper: Du, Y.H., Fang, J. and $\mathrm{Hu}$, J. (2019) Research on the Equilibrium of a Revenue Sharing Contract in a Transfer-Operation-Transfer Project Based on the Theory of Share Tenancy. American Journal of Industrial and Business Management, 9, 1111-1135.

https://doi.org/10.4236/ajibm.2019.95076

Received: March 12, 2019

Accepted: May 11, 2019

Published: May 14, 2019

Copyright $\odot 2019$ by author(s) and Scientific Research Publishing Inc. This work is licensed under the Creative Commons Attribution International License (CC BY 4.0).

http://creativecommons.org/licenses/by/4.0/

(C) (i) Open Access

\begin{abstract}
To solve the transfer-operate-transfer (TOT) project contract model selection, contract structure optimization and the largest revenue of government and private partners, a revenue-sharing contract (RSC) structure equilibrium model of a TOT project is constructed based on the theory of share tenancy. According to the key parameters of RSC structure, the algebraic model is constructed by using the Lagrange multiplier method, and the geometric model is built by adopting the dynamic equilibrium method. The equilibrium conditions of the two models are obtained under the constraints of the maximization of income of both parties, and the equilibrium conditions of two models are verified as completely consistent. The result shows that 1) The RSC structure of the TOT project can achieve Pareto optimality and maximize revenue for both parties; 2) As the proportion of participants' investment or risk sharing increases, their revenue-sharing ratio (RSR) will increase, and vice versa; 3) Regardless of transaction costs, the three contract models are equivalent; considering the transaction costs, the revenue share of the government in the RSC is greater than that in the equilibrium state. 4) Changing the assumptions, the equilibrium model can still provide ideas for revenue sharing contract structure and efficiency optimization.
\end{abstract}

\section{Keywords}

Transfer-Operation-Transfer, Revenue-Sharing Contract, Revenue-Sharing Ratio, Equilibrium 


\section{Introduction}

In recent years, the public-private partnerships (PPPs) model has been widely used in various industries [1] [2], providing an effective model for infrastructure and public services [3] [4]. The types of existing PPP projects contain transfer-operate-transfer (TOT), rehabilitate-operate-transfer (ROT), operate and management (O\&M), and management contract (MC) models [5] [6]. The PPPs model is a contractual relationship formed among the involved parties that clarifies the rights, responsibilities, and benefit allocations of all participants, as well as the rational allocation of project surpluses [7]. It emphasizes that government and the private partner share the investment, revenue, and risk [8]. The PPPs project contract is a scheme to achieve revenue sharing between government and the private partner [9], and its investment returns are fixed-price contracts, revenue sharing contracts (RSCs), and wage contracts [10]. RSCs are usually used because of their greater flexibility and efficiency [9] [11]; there are revenue sharing provisions in many PPPs project contracts [12]. To determine whether RSCs are more efficient, Song et al. [13] used the RSC to solve the revenue sharing between suppliers and retailers. Qian et al. [14] proposed RSC to solve the unbalanced distribution of profits in the dairy product supply chain. In addition, contract flexibility and adaptability for PPP projects is more important than the traditional procurement model [15], which is crucial for solving the uncertainties of PPP projects [16]; when the situation becomes unfavorable to any party, the contract clause can be adjusted [17]. On the other hand, the contract terms are determined by its nature and structure, which are related to the requirements of the PPP project [18]. The TOT model is a common model in existing PPP projects. It is the government that transfers the concession rights of existing projects to the private partner through the concession, and it brings about the cooperation between the two parties. Due to the long duration of the concession and the large uncertainty of the TOT project, the contract usually includes revenue-sharing clauses. Therefore, the research on the balance of the TOT project RSC structure is crucial for the government and private partners to choose the contract model, optimize the contract structure, improve project efficiency, and achieve mutual win-win situation.

The TOT project's RSC structure and obtaining an equilibrium solution of the parameters are keys to choosing the contract model, optimizing the contract structure, and maximizing the revenue of both the government and the private partner. Research on RSC structures and their parameters has attracted the attention and favor of scholars at home and abroad [19] [20]. Shen et al. [21] proposed an improved BOT bargaining concession model based on bargaining theory to determine the franchise period. However, they did not give adequate consideration to the optimal relationship between the scale of government investment and the franchise period. Kang et al. [22] constructed a financial decision model based on discounted cash flow and the net present value method. They considered franchise fee and the financial characteristics of BOT projects from a government perspective. However, they did not consider the influences 
on revenue sharing of the relationship and the opportunity costs of the two parties. In addition, Wang et al. [10] and Ke et al. [23] analyzed the efficiency and success of the project in terms of the risk distribution between public and private partners. Schepper et al. [24] believed that stakeholders considered that the contract encouraged an adversarial relationship. The above-mentioned researchers have conducted in-depth studies on the factors affecting the franchise period, franchise fee, risk sharing, and conflicts of interests among PPP project stakeholders. This shows that the research on contract parameters is mostly based on the financial model, paying more attention to the determination of a certain parameter of the contract structure rather than the relationship and law between the contract structure parameters from the perspective of the system. They have paid more attention to the competitive economic interests of the government and the private partner but they have neglected cooperation. And they have rarely analyzed the relationship between the franchise period and the life cycle of the TOT project. Therefore, it is necessary to establish an overall equilibrium model of RSC structure based on the principle of maximizing the opportunity cost of both parties and the rest life cycle of TOT projects to ease the adversarial relationship between government and the private partner, and to avoid franchise period becoming relatively independent of the rest life cycle of TOT projects, and to finding the equilibrium condition of the RSC structure to provides the basis for the choice of the contract model for participants, the optimization of the contract structure, and the design of the specific parameters of the contract terms.

To solve the above problems, this paper discusses research on the balance of RSC structure for TOT projects based on the theory of share tenancy. First, the key parameters of the RSC for TOT project are identified based on the theory of share tenancy, and the RSC framework of the TOT project is constructed. Second, using the principle that the marginal cost of the element is equal to the marginal revenue, the proportion of advantageous resources for both parties is optimally allocated to achieve the best project output. Third, under the principle of maximizing the opportunity cost of both parties, RSR is determined, and eventually the RSC structure will be balanced and the contract efficiency will be improved. Finally, the balanced changes in RSC structure are discussed under different production efficiencies of the private partner and different government investment scales.

The chapters are as follows. The next part is a literature review. The third part establishes and solves for the algebraic and geometric equilibrium of the RSC structure respectively. The fourth part analyzes the results of the model equilibrium. The fifth part expands the original hypothesis conditions. The last part offers some conclusions and future research directions.

\section{Literature Review}

\subsection{Theoretical Basis for RSC}

Figure 1 gives a schematic diagram of the evolution and core ideas of the theory 
of share tenancy. Sharecropping contracts originated in agriculture [20]; the ideas can be traced back to the great economist Adam Smith in the period of classical economics, and Smith believed that sharecropping contracts led to an inefficient allocation of resources, according to an analogy with a tax known as tax equivalence. Next, in the neo-classical economics, Marshall inherited Smith's tax equivalence model and proved the inefficiency of sharecropping using geometric analysis. This is called the Marshall Puzzle. Cheung [25] believed that irrespective of transaction costs, renting contracts, RSCs, and wage contracts are equally efficient, which resolves the Marshall Puzzle, and Cheung proposes a generalized RSC theory for multiple industries-the theory of share tenancy.

The theory of share tenancy deals with resource allocation in the RSCs. Its core ideas include the RSC having a contract structure, and the RSC structure affecting the efficiency of the resource allocation [26]. The RSC of the theory of share tenancy refers to the clear agreement between the landlord and the tenant to a certain time period, the amount of land, the input of the tenant and the crops planted, and the landlord charging rent according to the agreement [27]. The RSC structure is defined, as are the transfer of use rights for production factors, and the rights of revenue distribution [26], which are generally represented by the proportion of production factors and the RSR. RSCs usually involve the rental or employment of factors of production, and any contract involving the rental or employment of factors of production must be structural [26]. In addition, under market competition, the proportion of production factors and RSR should be in balance to achieve the optimal allocation of resources. In the TOT project, the private partner rents the project assets or purchases all or part of the use rights of the project within agreed certain period. The government obtains a certain proportion of the project revenue through franchise fee or annual rent to achieve cooperation between the government and the private partner. Therefore, the TOT project RSC must also have its structure, and balance of its structure is the prerequisite for achieving optimal allocation of resources between the two parties.

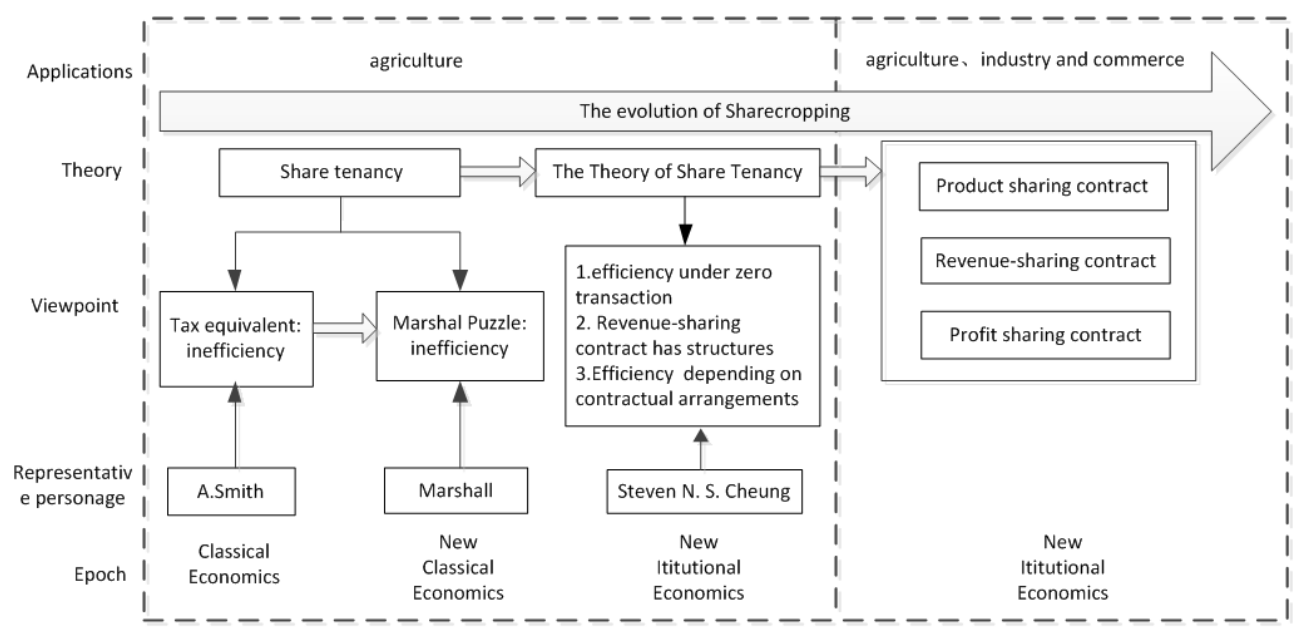

Figure 1. The evolution and core ideas of the theory of share tenancy [25]. 


\subsection{Study of the Key Parameters of RSC Structure}

The key parameters of the RSC structure basis, and balance of the key parameters affect the success of the RSC. The balance of the TOT project RSC structure depends on its key parameters in coordination with each other, which are the investment of private partner, franchise period, franchise fee, income of private partner, and the RSR [3].

In terms of franchise period, Shen et al. [28] proposed an alternative concession model for BOT that determines the effective interval of franchise period for both government and private investors. However, the specific franchise period also requires negotiation between the two parties. Shen et al. [21] adopted a bargaining theory (the Rubinstein model) to improve this model, and they established a BOT bargaining concession model to determine the specific franchise period. Hanaoka et al. [29] proposed a method for determining a reasonable franchise period using Monte Carlo simulations and bargaining game theory. Eduardo et al. [30] proposed a mechanism based on variable-term concession contracts-"least-presence-value of revenue" (LPVR) - to determine the franchise period. Based on the LPVR model, Nombela et al. [31] proposed a two-dimensional pricing model (least-present-value of net revenue; LPVNR). Most of the studies in the above literature are based on the government's position, and they have carried out multi-angle and continuous research on the franchise period study. By adjusting the franchise period to balance the interests of the two parties, either they neglected cooperation between the government and the private partner, or they gave insufficient consideration to the opportunity costs of the private partner in project income distribution.

Kang et al. [9] established a bi-level programming (BLP) model, and they used a heuristic algorithm to determine franchise fee. Niu et al. [32] optimized the BLP for charging, capacity, and franchise period, and they studied the influence of demand uncertainty on BOT contract design. Scandizzo et al. [33] used real option theory to establish a bargaining model between government and the private partner, reaching an agreement on the length of the contract and the franchise fee to resolve the balance of interests. In the above literature, the theories of net present value, agency theory, simulation, bargaining game theory, and genetic algorithm were used to optimize and adjust the franchise period. These research methods can analyze the financial feasibility of the project. They can balance the interests of both parties by adjusting the franchise fee. However, they do not consider the optimal proportion of franchise period and investment of private partner, or the impact opportunity cost of private partner on franchise fee.

Carbonara et al. [34] proposed a net benefits model for evaluating and measuring different energy performance contract (EPC). The difference in net profits between private and public sectors was minimized to balance their benefits. However, the model did not take into account the contribution rates from all parties involved. Li et al. [34] used the Shapley value to calculate the government and private revenue distribution in a sewage treatment project, both considering 
risk factors and without considering risk factors. Xu et al. [35] used the Shapley value method to determine the risk shares and returns of the relevant government agencies, the private partner, users, and design units in the PPP project under force majeure risk. The Shapley value determines the revenue distribution according to the marginal contributions of the participants, and it avoids the drawbacks of minimizing the net present value difference. However, it does not consider the impact of the optimal proportion between the franchise period and the investment of private partner on the output of the TOT project.

In addition, in the study of other factors that affect revenue distribution, the sharing of risks [36], and the partnership between government and the private partner [33] have a certain influence on the revenue distribution of RSC. Iossa et al. [15] used payment mechanisms to allocate demand risks. Iseki et al. [17] believed that the government should pursue the optimal allocation of risks, costs, and benefits rather than maximizing the risk transfer to the private sector or securing the highest upfront franchise fee. In addition, there is a delicate balance between government interests and interests of private partner [37]. Lahdenper [38] proposed that employers and contractors in the RSC can better consider each other's views to cooperate more effectively. In the RSC, proportionality based on $\mathrm{f}$ franchise fee, franchise period, investment of private partner, and tax rates, risk sharing has been included [39]. At the same time, the RSC implies a competition and cooperation relationship between the government and the private partner. When the project outputs, the two parties are cooperative, and they coordinate the resources allocation of both parties through cooperation. When the revenue is distributed, the two parties compete for interests and strive for their own opportunity cost maximization; under market competition, the two sides achieve a win-win situation through cooperation and competition.

\subsection{RSC Efficiency Study}

The RSC efficiency is the result of the equilibrium in the RSC structure. Sheu [40] used a two-level Stackelberg game to analyze the RSC between suppliers and retailers, and Sheu concluded that under equilibrium conditions, the total profit of channels with RSC is greater than the total channel revenue without it. Lippman et al. [41] established a model using the Nash bargaining method to conclude that cost plus premium contracts outperformed all other cost-sharing contracts. Shang et al. [42] used the Rubinstein bargaining game theory to establish a bargaining model of energy efficiency distribution in the revenue sharing of the EPC, and they obtained a bargaining interval that was satisfactory for both parties through the game. Qiu et al. [43] examined the efficiency of BOT contracts in the case of coexistence of incentive and monopoly issues, but they did not consider the optimality of private and public ownership or the optimization of the combination of the two parties. Martimort [44] mainly studied the contractual efficiency between public and private sectors in public utilities through principal-agent theory and the irrelevance theorem. According to the above lite- 
rature research and analysis, RSCs have been applied more maturely in the oil and supply chain areas, and the efficiency of RSCs has been proved through practice, but RSCs have been used less frequently in TOT projects.

Thus, it is clear that most of the research on the franchise period or franchise fee, the use of agency theory, simulation, bargaining game theory, genetic algorithms, etc. has examined the financial feasibility of PPP projects and the balance of interests of both parties. However, there has been insufficient consideration of optimizing the proportion between private partner investment and franchise period, and the income distribution, while maximizing the interests of both parties. At the same time, the literature has paid more attention to the competition between the government and the private partner, and it has ignored the cooperation between the two parties. In essence, the PPP project emphasizes cooperation between the government and the private partner to achieve revenue sharing and risk sharing. Therefore, based on the results of the application of RSCs in the oil, supply chain, PPP projects, and the characteristics of TOT projects, this paper reports on a balanced study of the RSC structure of TOT projects.

\section{Model Establishment and Solution}

\subsection{Related Concepts}

The TOT project in this study refers to the operational TOT project (hereinafter referred to as the TOT project), which refers to the rest life of the TOT project as $T$, and $t$ is the franchise period of the individual private partner in the project.

\section{Definition 1. Government investment.}

Government investment (including the cost of risk sharing) is $\alpha C_{f},(0 \leq \alpha \leq 1)$, and $\alpha$ is constant. where $\alpha=w_{f} \eta_{f g}+w_{r} \eta_{r g}, w_{f}+w_{r}=1$, $\eta_{f g}+\eta_{r g}=1, C_{f} \leq C_{T}, C_{T}$ is franchise fee that matches $T . C_{f}$ is franchise fee that matches $t$. In order to simplify the model, $C_{f}$ contains the initial working capital and risk costs of the project.

When $\alpha=0$, it indicates that the private partner pays the government franchise fee of franchise period at one time. This mode is a common TOT mode, namely the fixed rent mode. When $\alpha=1$, franchise fee is recovered through the government revenue share during franchise period, that is, the concession leasing model, at which time the contract is complete RSC. When $0<\alpha<1$, it is equivalent to the cooperation between the government and private partner in a fixed rent contract plus RSC.

The opportunity cost of the government investment is $\alpha C_{f} \times i_{g}, i_{g}=1+i_{*}$, where, $i_{g}$ is opportunity cost of unit government investment, $i_{*}$ is social benchmark rate of return.

\section{Definition 2. Investment of private partners.}

The private partners in "Circular of the Ministry of Finance on Issuing the Operational Guidelines for Public-Private Partnership Mode (for Trial Implementation)" (2014) [45] refers to domestic and overseas enterprise legal entities with a modern enterprise system already established, excluding financing platform com- 
panies under local governments and other state-owned holding enterprises.

$(1-\alpha) C_{f}$ denotes initial investment of private partner.

$1-\alpha=w_{f} \eta_{f c}+w_{r} \eta_{r c}, \eta_{f c}+\eta_{r c}=1$.

The opportunity cost of the investment of private partner is $(1-\alpha) C_{f} \times i_{c}$.

$i_{c}=1+i_{0}$ where $i_{c}$ is the unit opportunity cost of investment of private partner and $i_{0}$ represents the industry average rate of return, which does not change with the investment amount.

\section{Definition 3. Project revenue.}

We assume that the production and operating form that are determined by the cooperation of both parties can maximize the value of the project. In other words, the investments of government and private partner are consistent with productive equilibrium. Both parties have the right to decide the production and operating form of the project. The net profit function is $R=P \times q\left(C_{f}, t\right)-C_{o}$, where, $q$ represents production, $P$ indicates the price of the product or service.

$C_{o}=\sum_{t=1}^{T_{1}} C_{o t}$ is the sum of the opportunity cost of the people, materials, machinery, technology and other resources required during franchise period. Where, $C_{o t}$ is the operating opportunity cost for the $t$-th year. It is assumed that the resources required for project franchise period are borne by the private partner.

Definition 4. Revenue of the government and private partner with individual private partner.

In this article, the revenue is generated during the franchise period because of the initial investment at the beginning of the period. The government revenue does not include the part of franchise fee at the beginning of the period.

Figure 2 shows the revenue of the government and private partner with individual private partner. The abscissa $T$ of the vertical supply curve represents the project life period. The ordinate $\frac{\text { Revenue }}{\text { Franchise period }}$ is the average revenue of the project during T. $\beta$ is the RSR of government. $\partial R / \partial t$ is the marginal revenue of the project. Holding $C_{f}$ constant, the curve $\partial R / \partial t$ is leaning to the right according to the law of diminishing marginal returns.

The marginal revenue of government is $\beta \cdot \partial R / \partial t$, that is, the increase in government revenue caused by the increase of one unit of franchise period. The revenue of government is $\beta \cdot R$, which is the area below $\beta \cdot \partial R / \partial t$.

The marginal revenue of private partner is $(1-\beta) \cdot \partial R / \partial t$, that is, the increase in the revenue of private partner caused by the increase of one unit of franchise period. The revenue of private partner is $(1-\beta) \cdot R$, which is the area between $\partial R / \partial t$ and $\beta \cdot \partial R / \partial t$ during the franchise period.

If the revenue of private partner is as high as or higher than its alternative earnings, and when $\partial R / \partial t>0$, the private partner will extend the franchise period as much as possible to increase its revenue. To maximize wealth, the government will raise its RSR, until $(1-\beta) \cdot R=(1-\alpha) C_{f} \cdot i_{c}$. 


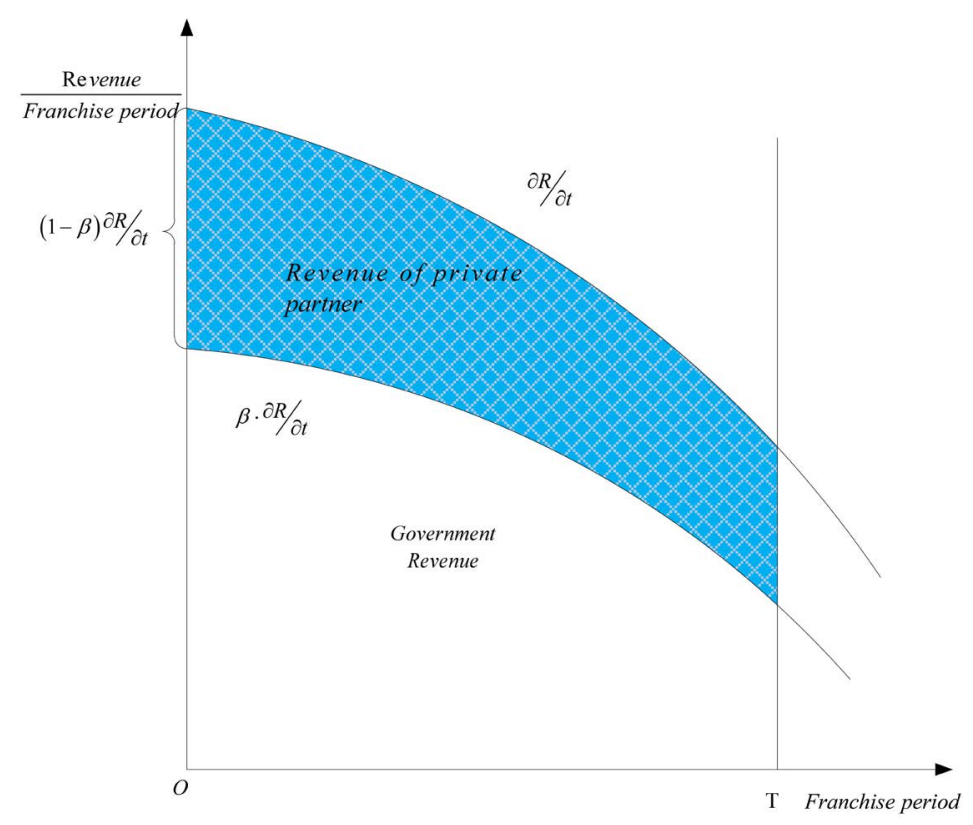

Figure 2, the revenue sharing with individual private partner [25].

Therefore, in a RSC, the amount of private partner investment contractually stipulated is essential, because the private partner would commit less if only the RSR was prescribed [46]. If the investment in franchise period is completely determined by private partner, it will control the amount of investment at the marginal cost, which is less than level of marginal product. This will be to inconsistent with equilibrium, and the parties will fail to reach an agreement. The TOT project is negotiated under the constraint of market competition. If the contract structure harms the interests of any of the parties, the contract will fail.

Definition 5. Revenue of government and private partners with multiple private partners.

We suppose that all private partners have the same investment and project production functions. If the investment of single private partner fails to meet the total investment demand in $T$, the government will divide $T$ into multiple franchise periods for multiple private partners. Figure 3 shows the revenue of government and private partners with multiple private partners.

The vertical lines $T_{1}, T_{2}, T_{3}, \cdots$ are dividing lines of the first, second and third private partner franchise periods respectively. The curves $(\partial R / \partial t)_{1},(\partial R / \partial t)_{2}$, $(\partial R / \partial t)_{3}$ are the marginal revenue curves of the project for each private partner. The curves $\beta(\partial R / \partial t)_{1}, \beta(\partial R / \partial t)_{2}, \beta(\partial R / \partial t)_{3}$ are respective marginal government revenue curves for each contract. The shaded areas show the total government revenues. The revenue of each private partner is shown by the area between $\partial R / \partial t$ and $\beta \cdot \partial R / \partial t$.

Similarly, to maximize wealth, the government will maximize the integral of marginal government revenue. This means that the revenue of each private partner will not exceed its opportunity cost. According to the law of diminishing marginal return, as the number of private partner increases, the growth rate of 


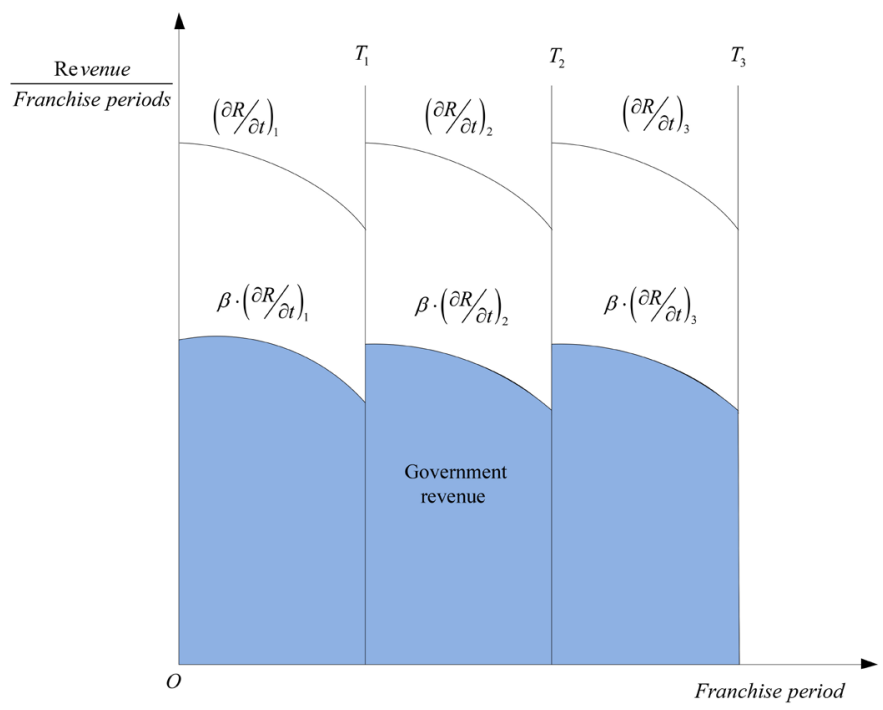

Figure 3. The revenue sharing with multiple private partners [25].

curve $\partial R / \partial t$ decreases, meanwhile, each private partner will get a shorter franchise period. The government RSR should be low for the private partner to gain its opportunity cost. As the curve $\beta \cdot \partial R / \partial t$ descends, the sum of the curve integrals of franchise period will be inverted $U$ shapes with the number of private partner increasing. That is, the total government revenue will increase first and then decrease as the number of private partner increases.

\subsection{Algebraic Model and Equilibrium Solution}

Assume that there are $\mathrm{m}$ private partners participating in the project, each of which has a franchise period of $t$, where, $t=T / m$.

$R_{g}=m \cdot \beta \cdot\left(P q-C_{o}\right)=m \cdot \beta \cdot R$ is the total government revenue when $m$ private partners participate the TOT project. To maximize $R_{g}$, the government needs to consider how to choose $m, \beta, C_{f}$ under the constraints of competition for multiple private partners (Note that $m$ and $C_{f}$ need not be treated separately, Given $C_{f}$, an adjustment of $m$ yields the same results as adjusting $C_{f}$ while holding $m$ constant. They are separated here to derive all the conditions in equilibrium conveniently). With the constraints of competition, that is,

$$
\max _{\left\{m, \beta, C_{f}\right\}} R_{g}=m \cdot \beta \cdot R,
$$

subject to $(1-\alpha) C_{f} \cdot i=(1-\beta) R$.

Create Lagrange expressions for maximum government revenue:

$$
L=m \cdot \beta \cdot R-\lambda\left[(1-\alpha) C_{f} \cdot i-(1-\beta) R\right]
$$

The necessary conditions are:

$$
\begin{gathered}
\frac{\partial L}{\partial m}=\beta \cdot R+m \cdot \beta \cdot \frac{\partial R}{\partial t} \cdot \frac{\mathrm{d} t}{\mathrm{~d} m}+\lambda(1-\beta) \frac{\partial R}{\partial t} \cdot \frac{\mathrm{d} t}{\mathrm{~d} m}=0 \\
\frac{\partial L}{\partial \beta}=m \cdot R-\lambda \cdot R=0
\end{gathered}
$$




$$
\begin{gathered}
\frac{\partial L}{\partial C_{f}}=m \cdot \beta \cdot \frac{\partial R}{\partial C_{f}}-\lambda\left[(1-\alpha) i-(1-\beta) \frac{\partial R}{\partial C_{f}}\right]=0 \\
\frac{\partial L}{\partial \lambda}=-\left[(1-\alpha) C_{f} \cdot i-(1-\beta) R\right]=0
\end{gathered}
$$

From Equation (2), we have

$$
m=\lambda
$$

According to $t=T / m$, there is

$$
\frac{\mathrm{d} t}{\mathrm{~d} m}=-\frac{T}{m^{2}}
$$

From the Equations (1)-(6), we can get

$$
\begin{gathered}
\beta=\frac{\partial R}{\partial t} / \frac{R}{t} \\
i=\frac{\partial R}{(1-\alpha) \partial C_{f}} \\
\beta=\frac{R-(1-\alpha) C_{f} \cdot i}{R}
\end{gathered}
$$

Finally solving Equations (7) and (9), we have

$$
\beta=\frac{\frac{\partial R}{\partial t}}{\frac{R}{t}}=\frac{R-(1-\alpha) C_{f} \cdot i}{R}
$$

Equation (7) indicates that the annual government revenue equals the marginal revenue of the project in equilibrium. Equation (8) shows that the marginal product of private partner equals the marginal cost in equilibrium. Equation (10) expresses that the RSR of government must simultaneously satisfy Equations (7) and (9) in equilibrium. In other words, in equilibrium, the revenue elasticity of project, $\frac{\partial R}{\partial t} / \frac{R}{t}$, equals the total revenue of the project minus the opportunity cost of private partner as a portion of the total revenue of project, which is government RSR as $\frac{R-(1-\alpha) C_{f} \cdot i}{R}$.

Under the hypothetical condition that the RSC structure is balanced, the number of private partner is $m$, therefore, we note the amount of individual private partner investment as $(1-\alpha) C_{f}^{*}$, the franchise fee as $C_{f}^{*}$ and the franchise period as $T^{*}$, government RSR as $\beta^{*}$.

\subsection{Geometric Model and Equilibrium Solution}

\subsubsection{Equilibrium of RSC Structure When the Initial Investment of Private Partner Is Less than the Stipulated Investment}

Using the relevant definitions in 3.1, this section analyses the geometric model equilibrium solution of RSC structure with the stipulated investment of a single private partner. This may result in the inability to fully utilize the remaining life 
of the TOT project, but it does not affect the final equilibrium result analysis.

Since $\alpha$ and $C_{f}$ are constant, the curve $\frac{(1-\alpha) C_{f} \cdot i}{t}$ is a rectangular hyperbola. The curve $\frac{R-(1-\alpha) C_{f} \cdot i}{t}$ represents the vertical distance between $\frac{R}{t}$ and $\frac{(1-\alpha) C_{f} \cdot i}{t}$, which represents the annual government revenue. Obviously, it should take into account the market competition to satisfy $(1-\alpha) C_{f} \cdot i=(1-\beta) R$ with the annual government revenue.

Figure 4 shows a schematic diagram of determining the franchise period and RSR with stipulated investment of a single private partner. The curve $\frac{R}{t}$ denotes average annual production of the project. The curve $\frac{(1-\alpha) C_{f} \cdot i}{t}$ represent the annual average opportunity cost of the private partner, and $\frac{R-(1-\alpha) C_{f} \cdot i}{t}$ is the average annual revenue of the government (annual rent). Then the equilibrium process can be analyzed dynamically as follow.

Step 1. If the investment of private partner is $(1-\alpha) C_{f}^{1}$, when $(1-\alpha) C_{f}^{1}<(1-\alpha) C_{f}^{*}$, the position of the curve $\frac{(1-\alpha) C_{f}^{1} \cdot i}{t}$ is low. If the investment of private partner gradually increases along the vertical axis, there is a upward shift of $\frac{(1-\alpha) C_{f}^{1} \cdot i}{t}$, and there is a corresponding upward shift of $\frac{R_{1}}{t}$

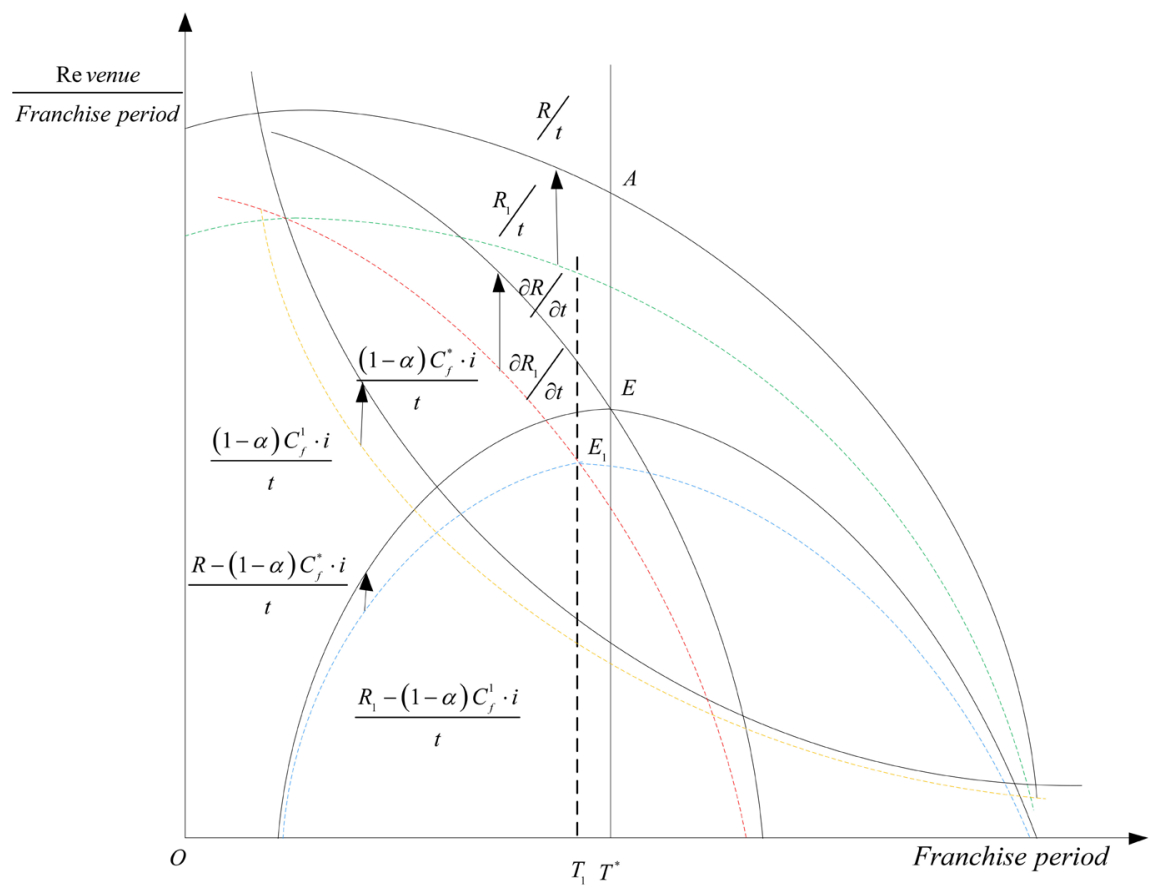

Figure 4. The determination of RSR and the franchise period under the stipulated investment of the individual private partner (1) [25]. 
too. In accordance with the law of diminishing marginal returns, when $\frac{(1-\alpha) C_{f}^{1} \cdot i}{t}$ at a constant rate; $\frac{R_{1}}{t}$ increases at a decreasing rate. The highest curve $\frac{R-(1-\alpha) C_{f}^{*} \cdot i}{t}$ is gained when the marginal upward shift of $\frac{(1-\alpha) C_{f}^{1} \cdot i}{t}$ and $\frac{R_{1}}{t}$ are equal, that is when the marginal revenue of private partner equals its marginal cost.

Step 2. The government determines the best franchise period along the horizontal axis. According to Definition 2 and the first step of 3.1.1,

$\frac{R-(1-\alpha) C_{f}^{*} \cdot i}{t}$ is the highest result derived from the alternative pairs of $\frac{(1-\alpha) C_{f} \cdot i}{t}$ and $\frac{R}{t}$. To maximize revenue, the government selects the highest point $E$ along with $\frac{R-(1-\alpha) C_{f}^{*} \cdot i}{t}$, at which time the government gains the biggest annual revenue. The franchise period corresponding with $E$ will be the best choice for government investment.

On the basis of the relationship between the marginal revenue curve and the average revenue curve, $\frac{\partial R}{\partial t}$ intersects with $\frac{R}{t}$ and $\frac{R-(1-\alpha) C_{f}^{*} \cdot i}{t}$ at their highest points respectively. The intersection of $\frac{\partial R}{\partial t}$ and $\frac{R-(1-\alpha) C_{f}^{*} \cdot i}{t}$ is $E$, which represents the equilibrium point. Therefore $E$ is the revenue-sharing point between the government and the private partner in the contract, $A T^{*}$ is the total income, $E T^{*}$ is the government revenue, and $A E$ is the revenue of private partner. $E$ determines the project franchise period and the RSR of government in accordance with the productive equilibrium of the $(1-\alpha) C_{f}^{*}$.

From Figure 3, in equilibrium, the RSR of government is

$$
\beta^{*}=\frac{E T^{*}}{A T^{*}}
$$

The average annual government revenue is

$$
E T^{*}=\frac{R-(1-\alpha) C_{f}^{*} \cdot i}{t}=\frac{\partial R}{\partial t}
$$

The average annual project output is

$$
A T^{*}=\frac{R}{t}
$$

According to Equation (15) and Definition 3,

$$
\frac{R-(1-\alpha) C_{f}^{*} \cdot i}{t}=\beta^{*} \cdot \frac{R}{t}
$$

Substituting Formulas (12), (13), and (14) into (11), we have 


$$
\beta^{*}=\frac{\frac{\partial R}{\partial t}}{\frac{R}{t}}=\frac{\frac{\left[R-(1-\alpha) C_{f}^{*} \cdot i\right]}{t}}{\frac{R}{t}}=\frac{R-(1-\alpha) C_{f}^{*} \cdot i}{R}
$$

Formula (15) is the geometric solution of the RSC equilibrium analysis with the stipulated investment of private partner.

\subsubsection{Balanced Process of RSC Structure When the Initial Investment of Private Partner Is More than the Stipulated Investment}

Figure 5 shows a schematic diagram of the franchise period and RSR with the stipulated investment of a single private partner.

If investment of the private partner is $(1-\alpha) C_{f}^{2}$ and $(1-\alpha) C_{f}^{2}>(1-\alpha) C_{f}^{*}$ as shown in Figure 5, the annual average revenue curve is $\frac{R_{2}}{t}$, the annual average cost curve of the private partner is $\frac{(1-\alpha) C_{f}^{2} \cdot i}{t}$, the average annual government revenue curve is $\frac{R_{2}-(1-\alpha) C_{f}^{2} \cdot i}{t}$, and the largest annual government revenue is $E_{2} T_{2}$, corresponding to the franchise period $T_{2}$. Obviously, $E_{2} T_{2}<E T^{*}$ fails to achieve the maximum annual government revenue. At this time, the government RSR is $\beta_{2}=\frac{E_{2} T_{2}}{A_{2} T_{2}}$. If the maximum annual government revenue reaches $E T^{*}$, its RSR needs to be improved to $\beta_{2}^{\prime}=\frac{E T^{*}}{A_{2} T_{2}}$, then the revenue of private partner must be impaired and its opportunity cost cannot be recovered. At this time, the private partner marginal revenue is less than its marginal cost, which can be improved through a reduction of investment, and meanwhile the opportunity cost reduces. When the marginal revenue is equal to the marginal cost, the investment of private partner just reaches $(1-\alpha) C_{f}^{*}$, and the annual government revenue curve is $\frac{R_{2}-(1-\alpha) C_{f}^{2} \cdot i}{t}$, its highest point is $E T^{*}$, the corresponding franchise period is $T^{*}$, and the RSR of government is $\beta^{*}=\frac{E T^{*}}{A T^{*}}$, which is the same as the equilibrium in 3.3.1.

\section{Analysis of the Results}

\subsection{Analysis of Consistency between Algebraic and Geometric Models}

In the TOT project RSC, the equilibrium solution of the algebraic model (10) is consistent with the equilibrium solution of the geometric model (15), which is $\beta=\frac{\frac{\partial R}{\partial t}}{\frac{R}{t}}=\frac{\frac{\left[R-(1-\alpha) C_{f}^{*} \cdot i\right]}{t}}{\frac{R}{t}}=\frac{R-(1-\alpha) C_{f}^{*} \cdot i}{R}$. Under equilibrium conditions, 


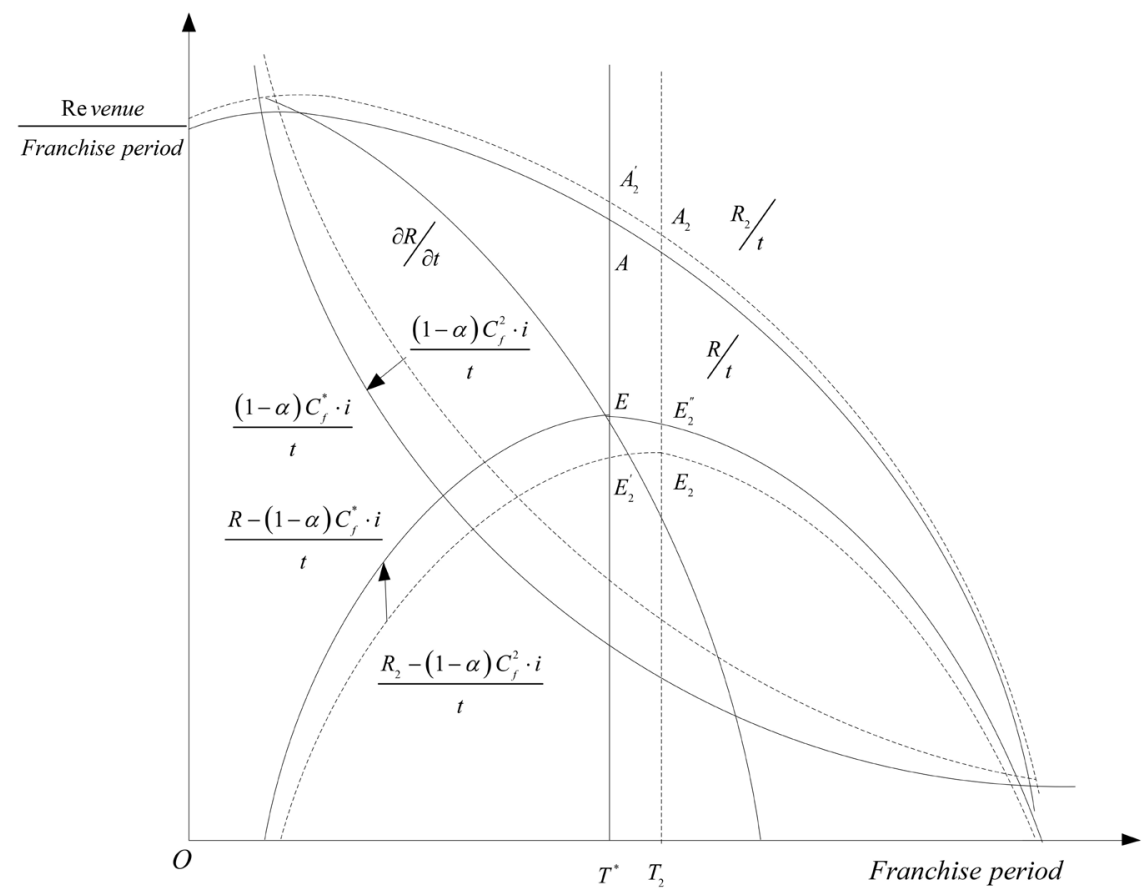

Figure 5. The determination of RSR and the franchise period under the stipulated investment amount of the individual private partner (2) [25].

the annual project revenue is equal to the marginal project revenue, and the marginal revenue of private partner is equal to its marginal cost. $\beta^{*}$ is equal to the revenue elasticity of the project and equal to the ratio of government revenue to project revenue. The equilibrium result determines $T^{*}$ and $\beta^{*}$, which are consistent with the production balance of $(1-\alpha) C_{f}^{*}$ and $C_{f}^{*}$. Therefore, the equilibrium solution realizes the optimization of the key parameters of the RSC structure and maximizes the revenue of both parties. In addition, when the RSC structure is balanced, there is $m=\frac{T}{T^{*}}$ that is, $m$ private partners participating in the TOT project can make full use of the remaining life cycle of the TOT project.

\subsection{Comparative Analysis of the Equilibrium Process between the Amount of Investment and the Amount of Investment That Has Been Established}

From the equilibrium process in Section 3.3, when $(1-\alpha) C_{f}<(1-\alpha) C_{f}^{*}$, the marginal revenue of private partner is greater than its marginal cost. The government can increase its annual revenue by increasing its RSR, and the private partner can increase its revenue by increasing investment to make up for the reduction with the government RSR increasing. Until $(1-\alpha) C_{f}=(1-\alpha) C_{f}^{*}$, the marginal revenue equals the marginal cost, and, at the same time, the annual government revenue reaches its highest point, that is equilibrium of the RSC structure. This equilibrium process is achieved through increases in the RSR of government, investment of private partner, and the franchise period. When 
$(1-\alpha) C_{f}>(1-\alpha) C_{f}^{*}$, the marginal revenue of the private partner is less than the marginal cost. The government can still make up for its annual revenue by increasing its RSR. The private partner can reduce its opportunity cost by reducing its investment amount. Until $(1-\alpha) C_{f}=(1-\alpha) C_{f}^{*}$, the private partner marginal revenue equals the marginal cost. At this time, the annual government revenue is at highest, and it determines the best RSR of the government, thus achieving equilibrium of the RSC structure. This equilibrium process is achieved through the increasing the government RSR, the reduction investment of private partner and the shortening the franchise period.

It shows that when the investment amount is inconsistent with $(1-\alpha) C_{f}^{*}$, the final equilibrium can be achieved by changing the three variables of government RSR, private partner investment amount, and franchise period toward the equilibrium solution, rather than through changing only one of the variables affecting the RSC structure. This result shows that it is necessary to consider system correlation among the key multiple parameters of the TOT project RSC, instead of simply changing a parameter for optimization of the non-equilibrium RSC structure.

\subsection{Analysis of the Impact of $\alpha$ on Equilibrium Results}

The equilibrium result shows that $\beta^{*}$ and $\alpha$ are positively correlated, what reflects more investment and risk, more benefit. In addition, according to Definition 1 and the equilibrium result, the TOT project revenue is $R$ which is equal to the opportunity cost of $C_{f}$. The franchise fee is $(1-\alpha) C_{f}$, the government investment is $\alpha C_{f}$, and its revenue is the opportunity cost of $\alpha C_{f}$; the investment and of the private partner is $(1-\alpha) C_{f}$, and its revenue is the opportunity cost of $(1-\alpha) C_{f}$. When $\alpha=0$, the franchise fee is $C_{f}$, and the government investment is 0 , so that the contract is a fixed rent contract of TOT project, the government revenue is 0 , the revenue of the private partner is the opportunity cost of $C_{f}$ with the investment of $C_{f}$. When $0<\alpha<1$, the franchise fee is $(1-\alpha) C_{f}$, and the government investment is $\alpha C_{f}$, the contract is a fixed rent contract plus RSC of TOT project, the government revenue is the opportunity cost of $\alpha C_{f}$, the revenue of the private partner is the opportunity cost of $(1-\alpha) C_{f}$; when $\alpha=1$, the franchise fee is 0 , and the government investment is $C_{f}$, the investment of private partner is 0 , so that the contract is RSC of TOT project, the government revenue is the opportunity cost of $C_{f}$, and the revenue of the private partner is 0 .

From the above analysis, if the transaction cost is not considered, the revenue of TOT project is opportunity cost of $C_{f}$ in the three contract modes, the revenue of each party is only related to $\alpha$, so the three contract modes are equivalent. In the fixed rent contract, the government bears the least uncertainty, and the private partner undertakes the greatest investment risk. In the complete RSC, the government has the greatest risk of uncertainty, and the private partner undertakes the least investment risk. Therefore, if transaction costs are considered, as $\alpha$ 
becomes larger, the greater is the proportion of the revenue-sharing clauses in the contract. To compensate for the increasing transaction costs borne by the government, the RSR of the government will increase with the increase of $\alpha$. At the same time, the RSR of the government will be greater than $\beta^{*}$ in the same condition, which is not considering transaction costs.

\section{Discussion}

\subsection{Equilibrium of the RSC Structure under Different Efficiency Levels with Established Investment}

In the original hypothesis, the efficiency level of private partners is the same, and the opportunity cost of a stipulated investment is determined in accordance with the industry average return rate. In practice, the efficiency of each private partner is different. The optimal equilibrium is determined according to the respective efficiency levels of private partner. The shape and the height of vertices of curve $\frac{R-(1-\alpha) C_{f} \cdot i}{t}$ are different for each private partner. The process of balancing RSC structure in different efficiency with the stipulated investment is discussed below.

\subsubsection{The Efficiency of Private Partner Is Higher than the Industry Average Level}

The efficiency of private partner is higher than the industry average level, that is, under the same stipulated capital investment, and the revenue of private partner is higher, so it also requires a higher return on investment. We note the investment of private partner is $(1-\alpha) C_{f}^{4}$. As shown in Figure 6, $\frac{R_{4}}{t}$ is the average annual revenue of the TOT project, which is higher than the industry average level, and $\frac{R_{4}-(1-\alpha) C_{f}^{4} \cdot i}{t}$ is the highest government rent curve with $(1-\alpha) C_{f}^{4}$. If there are no transaction costs, then according to the principle that the marginal cost is equal to marginal revenue of each factor, the highest point of $\frac{R_{4}-(1-\alpha) C_{f}^{4} \cdot i}{t}$ is $E_{4} T_{4}^{\prime}$, corresponding to the annual maximum rent of the government. Obviously $E_{4} T_{4}^{\prime}>E T_{1}$, and the annual average revenue of $(1-\alpha) C_{f}^{4}$ is $\frac{(1-\alpha) C_{f}^{4} \cdot i}{t}$. However, taking the transaction costs into consideration, the government cannot get the highest rent $E_{4} T_{4}^{\prime}$. One hand, the government cannot obtain the real information about the efficiency of each private partner, which means that the government needs to pay significant information costs to obtain information on real efficiency of each private partner; on the other hand, there is also competition between different TOT project, if the government want the highest rent $E_{4} T_{4}^{\prime}$, then $(1-\alpha) C_{f}^{4}$ will selected the TOT project in which the government annual rent is $E T^{*}$ rather than $E_{4} T_{4}^{\prime}$. Therefore, considering transaction costs, the government can only get the rent $E T^{*}$ corresponding to 


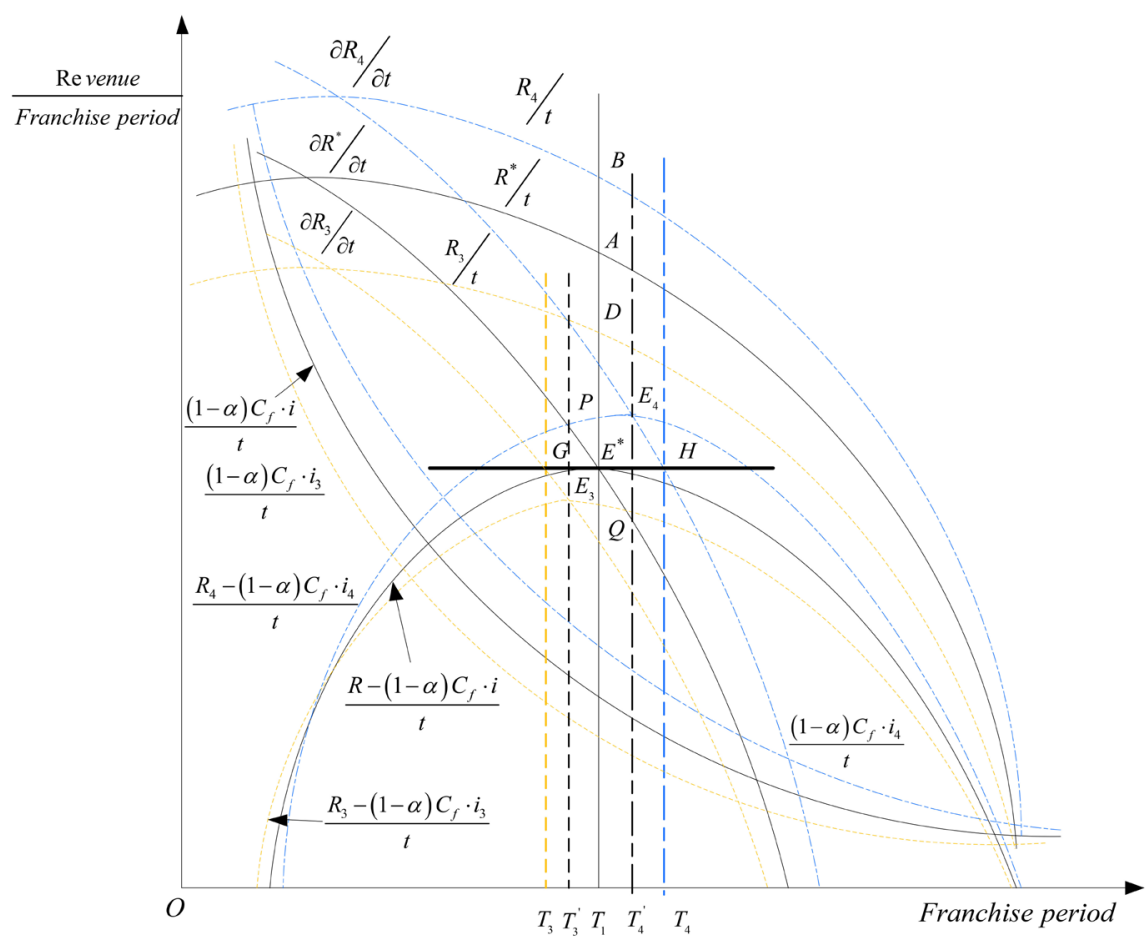

Figure 6. Equilibrium of RSC structure under different efficiency with the stipulated investment [25].

the highest point of the curve $\frac{R-(1-\alpha) C_{f} \cdot i}{t}$ under market competition.

Case 1: According to the industry average level, assume that the franchise period of $(1-\alpha) C_{f}^{4}$ is $T^{*}$. As shown in Figure 6, the average annual revenue of the TOT project is $B T^{*}$, and the opportunity cost of $(1-\alpha) C_{f}^{4}$ is $B P$, which is theoretically the highest government revenue that can reach $P T^{*}$. However, considering market competition and transaction costs, the government can only gain rents $E T^{*}$, then $(1-\alpha) C_{f}^{4}$ can gain the revenue $B E$, which is higher than its opportunity cost $B P$, meanwhile, it is higher than the average opportunity cost of the industry $A E$, and it includes the TOT project rent $P E$ transferred from the government to $(1-\alpha) C_{f}^{4}$. In other words, $(1-\alpha) C_{f}^{4}$ is the intra-marginal cooperator who will obtain revenue that is higher than the average opportunity cost of the industry.

Case 2: If the franchise period is selected by $(1-\alpha) C_{f}^{4}$, according to the government rent $E T^{*}$. The marginal revenue of the TOT project is equal to its average marginal cost, that is, when $\partial R_{4} / \partial t=E T^{*}$, as shown in Figure 6, the franchise period is $T_{4}$, corresponding to the intersection point of the curve $\partial R_{4} / \partial t$ and curve $G H$. Apparently, $(1-\alpha) C_{f}^{4}$ can negotiate with the government for a longer franchise period when the government revenue is $E T^{*}$.

\subsubsection{The Efficiency of Private Partner Is Lower than the Industry Average Level}

The efficiency of private partner is lower than the industry average level, which 
means that with the same funds, the revenue is low. The investment of private partner is recorded as $(1-\alpha) C_{f}^{3}$, which equals $(1-\alpha) C_{f}^{*}$. The average revenue during the franchise period is $R_{3} / t$ as shown in Figure 6, which is below the industry average, and the curve $\frac{R_{3}-(1-\alpha) C_{f}^{3} \cdot i}{t}$ is the highest government rent curve with $(1-\alpha) C_{f}^{3}$. If there are no transaction costs, with the principle that the marginal cost and marginal revenue of each factor are equal, the annual maximum rent of the government is $E_{3} T_{3}^{\prime}$, corresponding to the highest point of the curve $\frac{R_{3}-(1-\alpha) C_{f}^{3} \cdot i}{t}$. Obviously, $E_{3} T_{3}^{\prime}<E T^{*}$, the annual average revenue of $(1-\alpha) C_{f}^{3}$ is $\frac{(1-\alpha) C_{f}^{3} \cdot i}{t}$. However, under market competition, the government will not choose $(1-\alpha) C_{f}^{3}$, whose annual maximum rent of the government below $E T^{*}$.

Case 1: Assume that the franchise period of $(1-\alpha) C_{f}^{3}$ is $T^{*}$, which is the industry average production level. As shown in Figure 6, when the franchise period is $T^{*}$, the average annual revenue of TOT projects for $(1-\alpha) C_{f}^{3}$ is $D T^{*}$, government rent is $E T^{*}$, and the revenue of $(1-\alpha) C_{f}^{3}$ is $D E$, which is lower than its opportunity cost $D Q$, and the part $E Q$ that belongs to opportunity cost of $(1-\alpha) C_{f}^{3}$ needs to be transferred to the government. In other words, $(1-\alpha) C_{f}^{3}$ is marginal partner, which will earn less than the average opportunity cost of industry. If $(1-\alpha) C_{f}^{3}$ cannot afford the loss of opportunity costs, it can only abandoned the cooperation with government.

Case 2: If the franchise period is selected by $(1-\alpha) C_{f}^{3}$, according to the government rent $E T^{*}$. When the marginal revenue is equal to its marginal cost in the TOT project with $(1-\alpha) C_{f}^{3}$, that is, when $\partial R_{3} / \partial t=E T^{*}, G$ is the intersection point of $\partial R_{3} / \partial t$ and $G H$ in Figure 6, the corresponding franchise period is $T_{3}$. Therefore, when the government revenue is $E T^{*},(1-\alpha) C_{f}^{3}$ can negotiate with the government for lower franchise period $T_{3}$ in exchange for cooperation opportunities.

Under the hypothetical condition of Figure 6, when the annual rent of the government is unchanged at $E T^{*}$, the equilibrium process in Figure 6 can be simplified as in Figure 7. As shown in Figure 7, the annual rent of the government is $R_{a}$, which remains unchanged and the rent of the government during the franchise period is $R_{g}=R_{a} t$. The franchise period of $(1-\alpha) C_{f}^{4}$ is $T_{4}$, from the parallel to $R_{g}=R_{a} t$. Similarly, the franchise period of $(1-\alpha) C_{f}^{3}$ is $T_{3}$. According to the franchise period determined by the industry average level, the revenue of $(1-\alpha) C_{f}^{4}$ is $E_{4}^{\prime} T^{*}$, which is higher than the industry average revenue, and the government RSR will be lower than the industry average level, that is $\beta_{4}<\beta^{*}$. By contrary, the revenue of $(1-\alpha) C_{f}^{3}$ is $E_{3}^{\prime} T^{*}$, which is below the industry average revenue, and the government RSR will be higher than the industry average level, that is $\beta_{3}>\beta^{*}$. Therefore, the government's highest rent according to the average level of the industry will be conducive for the high-efficiency 


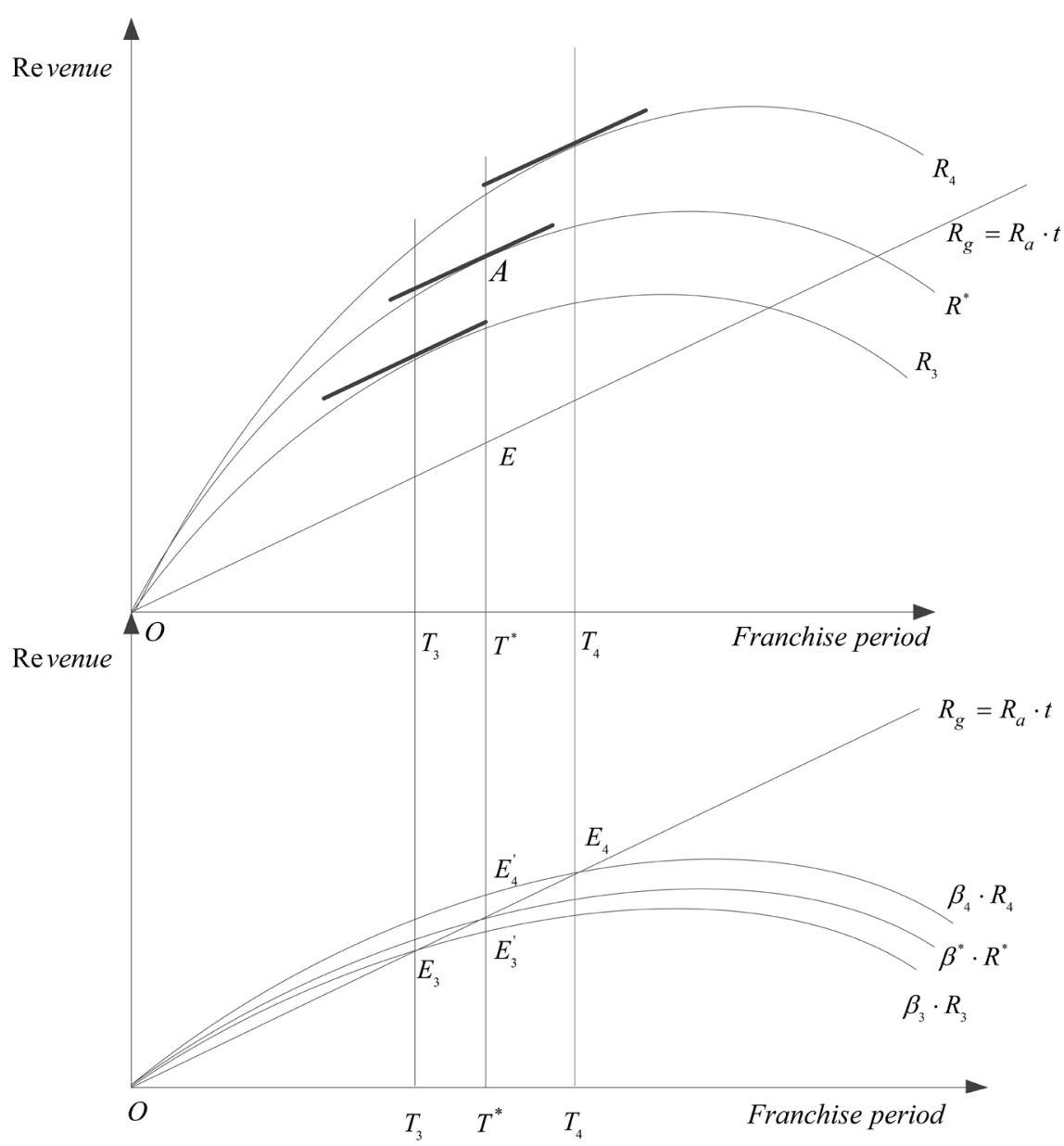

Figure 7. Equilibrium of RSC structure of the stipulated investment and government rents.

private partner to gain higher revenue sharing. At the same time, it will prevent low-efficiency private partner from participating in the operation of the TOT project. This is in line with the TOT model to improve efficiency of the existing project.

\subsection{Changes in the RSR under Government Involvement in Project Operation Investment}

The original hypothesis is that project operations investment in all is borne by private partner. Now suppose the government involved in operations, but the total investment is unchanged, and the corresponding revenue of the TOT project remains unchanged. That is $C_{o}=C_{s o}+C_{g o}$, where $C_{g o}$ is the sum of the opportunity cost of the people, materials, machinery, technology and other resources required undertaken by government during franchise period, $C_{s o}$ is the sum of the opportunity cost of the people, materials, machinery, technology and other resources required undertaken by private partner during franchise period. $C_{g o}$ is the government operating investment revenue, then the total government revenue including the operation investment opportunity cost is $C_{g o}+\beta^{*} R$. $C_{\text {so }}$ 
is the operating investment revenue of private partner, then the total revenue of private partner including the operation investment opportunity cost is $C_{\text {so }}+\left(1-\beta^{*}\right) R$. Then the RSR of government under government involvement in project operations is $\beta_{o}=\frac{C_{g o}+\beta^{*} R}{R+C_{0}}$.

As the operating investment of government increases, $C_{g o}$, and $C_{g o}+\beta^{*} R$ increase, and $\beta_{o}=\frac{C_{g o}+\beta^{*} R}{R+C_{0}}$ increases because of $R+C_{0}$ being constant. The result is consistent with the principle of who invests and who benefits.

\section{Conclusions}

In this paper, aiming at the problem of the TOT project contract model selection, contract structure optimization and the largest revenue of government and private partner, the equilibrium analysis of RSC in a TOT project based on the theory of share tenancy is proposed, and the main research work of this paper is as follows:

1) This paper identified and defined the crucial parameters of RSC structure in a TOT project under the theory of share tenancy, which are the investment of private partner, franchise period, government revenue and the revenue of private partner, and government RSR. Without considering the transaction costs and the time value of money, the equilibrium solution of the mathematical model constructed by the Lagrange multiplier method is $\beta=\frac{\partial R}{\partial t} / \frac{R}{t}=\frac{R-(1-\alpha) C_{f}^{*} \cdot i}{R}$. The equilibrium solution of the geometric model which is established by the dynamic equilibrium method is $\beta=\frac{E T^{*}}{A T^{*}}=\frac{\partial R}{\partial t} / \frac{R}{t}=\frac{R-(1-\alpha) C_{f}^{*} \cdot i}{R}$.

2) Comparing the equilibrium solutions of the mathematical model and the geometric model, the solutions of the algebraic model and the geometric model are verified as completely consistent, and the equilibrium solution determines $T^{*},(1-\alpha) C_{f}^{*}$, that is $C_{f}^{*}$, and $\beta^{*}=\frac{R-(1-\alpha) C_{f}^{*} \cdot i}{R}$. By comparing the equilibrium results of different initial states in the geometric model, under the same assumptions; if the three variables of government RSR, investment of private partner, and franchise period simultaneously shift toward the direction of balanced solution, then it can arrive Pareto optimum in equilibrium. It is a win-win situation through cooperation and competition under in market, and it eases the adversarial relationship between government and the private partner. At the same time, the number of the private partner, $m=T / T^{*}$ is determined, then the equilibrium can make full use of remaining life cycle of the TOT project.

3) $\beta^{*}$ is positively correlated with $\alpha$. Regardless of considering transaction costs or not, $\beta^{*}$ will increase with the increase of $\alpha$. If the transaction cost is not considered, the fixed rent contract of TOT project $(\alpha=0)$, the fixed rent contract plus RSC of TOT project $(0<\alpha<1)$ and the RSC of TOT project $(\alpha=1)$ 
are equivalent. If the transaction cost is considered, the RSR of the government will be greater than $\beta^{*}$ which is not considering transaction costs.

4) If franchise period is determined by $T^{*}$, considering transaction costs, the revenue of efficient private partner is higher than the industry average level and higher than its opportunity cost. On the other hand, the revenue of inefficient private partner is lower than the industry average level, and the private partner needs to transfer part of the opportunity cost to the government. If government rent is determined by $E T^{*}$, efficient private partner can obtain a longer franchise period, and inefficient private partner gets a shorter franchise period.

5) If the government participates in the project operation investment, the total revenue including the operation investment opportunity cost will increase as the operation investment increases, which is consistent with the principle of who invests and who benefits.

In summary, the main contributions are as follow. 1) The RSC structure equilibrium model of a TOT project is constructed based on the theory of share tenancy, which indicates that the RSC of TOT projects can reach the Pareto optimum in equilibrium, which maximizes the revenues of the government and the private partner. 2) The equilibrium of RSC structure can ease the adversarial relationship between government and the private partner, and can make full use of remaining life cycle of the TOT project, which is not solved in previous models (e.g. financial decision model, bi-level programming (BLP) model, bargaining model). 3) When the assumptions differ, the theory of share tenancy provides the idea of optimizing the contract efficiency from the perspective of the structure of RSC, and it achieves an equilibrium of RSC in TOT projects.

In this paper, the original theoretical assumptions without considering the time value of money and transaction costs, is to simplify the theoretical derivation. If considering the time value of money, according to the present value, then the total revenue will be smaller than without considering the time value of money, and the curve which contains the revenue will be lower, so the equilibrium results will be changed. However the equilibrium results are also in accord with the structural equilibrium model of TOT project revenue sharing contract equilibrium principle. In the discussion in part 5 , we have discussed the cases for considering transaction costs. Although the original assumptions such as the transaction costs have been expanded during the discussion, the time value of money, and transaction costs are worthy of further exploration to expand the application.

\section{Conflicts of Interest}

The authors declare no conflicts of interest regarding the publication of this paper.

\section{References}

[1] Chen, C. and Doloi, H. (2008) BOT Application in China: Driving and Impeding 
Factors. International Journal of Project Management, 26, 388-398. https://doi.org/10.1016/j.ijproman.2007.07.002

[2] Almarri, K. (2016) Improving PPP Contract Design for Procurement of Public Projects. The 10 th International Conference on Project Management, Gold Coast, Australia, November 2016, 19-27.

[3] Ng, S.T., Xie, J., Cheung, Y.K. and Jefferies, M. (2007) A Simulation Model for Optimizing the Concession Period of Public-Private Partnerships Schemes. International Journal of Project Management, 25, 791-798. https://doi.org/10.1016/j.ijproman.2007.05.004

[4] Cheng, Z., Ke, Y., Lin, J., Yang, Z. and Cai, J. (2016) Spatio-Temporal Dynamics of Public Private Partnership Projects in China. International Journal of Project Management, 34, 1242-1251. https://doi.org/10.1016/j.ijproman.2016.05.006

[5] Zhang, X. (2005) Financial Viability Analysis and Capital Structure Optimization in Privatized Public Infrastructure Projects. Journal of Construction Engineering \& Management, 131, 656-668.

https://doi.org/10.1061/(asce)0733-9364(2005)131:6(656)

[6] Song, H. and Gao, X. (2018) Green Supply Chain Game Model and Analysis under Revenue-Sharing Contract. Journal of Cleaner Production, 170, 183-192. https://doi.org/10.1016/j.jclepro.2017.09.138

[7] Almarri, K. and Blackwell, P. (2014) Improving Risk Sharing and Investment Appraisal for PPP Procurement Success in Large Green Projects. Procedia-Social and Behavioral Sciences, 119, 847-856. https://doi.org/10.1016/j.jclepro.2017.09.138

[8] Shan, X.Q. and Ye, X.S. (2012) Research on Public-Private Financing Mode of Public Rental Housing and Its Selection. 2012 International Conference on Management Science \& Engineering 19th Annual Conference Proceedings, Dallas, TX, 20-22 September 2012, 1787-1793. https://doi.org/10.1109/icmse.2012.6414414

[9] Kang, C.C., Feng, C.M. and Kuo, C.Y. (2011) A Royalty Negotiation Model for BOT (Build-Operate-Transfer) Projects: The Operational Revenue-Based Model. Mathematical \& Computer Modelling, 54, 2338-2347. https://doi.org/10.1016/j.mcm.2011.05.042

[10] Wang, Y. and Liu, J. (2015) Evaluation of the Excess Revenue Sharing Ratio in PPP Projects Using Principal-Agent Models. International Journal of Project Management, 33, 1317-1324. https://doi.org/10.1016/j.ijproman.2015.03.002

[11] Abhishek, V., Hajek, B. and Williams, S.R. (2013) Auctions with a Profit Sharing Contract. Games \& Economic Behavior, 77, 247-270. https://doi.org/10.1016/j.geb.2012.10.007

[12] Ortiz, I.N. and Buxbaum, J.N. (2008) Protecting the Public Interest in Long-Term Concession Agreements for Transportation Infrastructure. Public Works Management \& Policy, 13, 126-137. https://doi.org/10.1177/1087724x08326175

[13] Song, J., Jin, L., Zhao, Y. and Hu, W. (2017) Using Bargaining-Game Model to Negotiate Compensation for the Early Termination of BOT Highway Projects. Transportation Research Part. A Policy \& Practice, 105, 197-209. https://doi.org/10.1177/1087724x08326175

[14] Qian, G.X., Zhang, Y.P., Jian-Guo, W.U. and Pan, Y.H. (2013) Revenue Sharing in Dairy Industry Supply Chain-A Case Study of Hohhot, China. Journal of Integrative Agriculture, 12, 2300-2309. https://doi.org/10.1016/s2095-3119(13)60585-7

[15] Iossa, E. and Martimort, D. (2015) The Simple Microeconomics of Public-Private Partnerships. Journal of Public Economic Theory, 17, 4-48. 
https://doi.org/10.1111/jpet.12114

[16] Sérgiodomingues, Dejanzlatkovic and Athenaroumboutsos (2014) Contractual Flexibility in Transport Infrastructure PPP. European Transport Conference 2014, Frankfurt, October 2014, 1-19.

[17] Iseki, H. and Houtman, R. (2012) Evaluation of Progress in Contractual Terms: Two Case Studies of Recent DBFO PPP Projects in North America. Research in Transportation Economics, 36, 73-84. https://doi.org/10.1016/j.retrec.2012.03.004

[18] Zhang, X. (2005) Critical Success Factors for Public-Private Partnerships in Infrastructure Development. Journal of Construction Engineering \& Management, 131, 3-14.

[19] Liu, J., Gao, R., Cheah, C.Y.J. and Luo, J. (2016) Incentive Mechanism for Inhibiting Investors' Opportunistic Behavior in PPP Projects. International Journal of Project Management, 34, 1102-1111. https://doi.org/10.1016/j.ijproman.2016.05.013

[20] Cotula, L. (2010) Investment Contracts and Sustainable Development: How to Make Contracts for Fairer and More Sustainable Natural Resource Investments. International Institute for Environment and Development, London.

[21] Shen, L.Y., Bao, H.J., Wu, Y.Z. and Lu, W.S. (2007) Using Bargaining-Game Theory for Negotiating Concession Period for BOT-Type Contract. Journal of Construction Engineering \& Management, 133, 385-392. https://doi.org/10.1061/(asce)0733-9364(2007)133:5(385)

[22] Kang, C.C., Feng, C.M. and Huang, S.C. (2007) A New Financial Engineering Model for Analyzing the Royalty of BOT Projects: The Taiwan Case. IEEE International Conference on Industrial Engineering and Engineering Management, Singapore, 2-4 December 2007, 277-281. https://doi.org/10.1109/ieem.2007.4419195

[23] Ke, Y., Wang, S.Q., Chan, A.P.C. and Lam, P.T.I. (2010) Preferred Risk Allocation in China's Public-Private Partnership (PPP) Projects. International Journal of Project Management, 28, 482-492. https://doi.org/10.1016/j.ijproman.2009.08.007

[24] Schepper, S.D., Dooms, M. and Haezendonck, E. (2014) Stakeholder Dynamics and Responsibilities in Public-Private Partnerships: A Mixed Experience. International Journal of Project Management, 32, 1210-1222. https://doi.org/10.1016/j.ijproman.2014.01.006

[25] Cheung, S.N.S. (1969) The Theory of Share Tenancy: With Special Application to Asian Agriculture and the First Phase of Taiwan Land Reform. The University of Chicago Press, Chicago and London, 3-4, 85-87.

[26] Cheung, S.N.S. (2014) The Choice of Institutional Arrangements (Economic Explanation, Book Four). China Citic Press, Beijing.

[27] Cheung, S.N.S. (1969) The Theory of Share Tenancy: With Special Application to Asian Agriculture and the First Phase of Taiwan Land Reform. The University of Chicago Press, Chicago and London, 3-4, 85-87, 84.

[28] Shen, L.Y., Li, H. and Li, Q.M. (2002) Alternative Concession Model for Build Operate Transfer Contract Projects. Journal of Construction Engineering and Management, 128, 326-330. https://doi.org/10.1061/(asce)0733-9364(2002)128:4(326)

[29] Hanaoka, S. and Palapus, H.P. (2012) Reasonable Concession Period for Build-Operate-Transfer Road Projects in the Philippines. International Journal of Project Management, 30, 938-949. https://doi.org/10.1016/j.ijproman.2012.02.001

[30] Engel, E.M.R.A., Fischer, R.D. and Galetovic, A. (2001) Least-Present-Value-of-Revenue Auctions and Highway Franchising. Journal of Political Economy, 109, 993-1020. https://doi.org/10.1086/322832 
[31] Nombela, G. and de Rus, G. (2004) Flexible-Term Contracts for Road Franchising. Transportation Research Part A: Policy and Practice, 38, 163-179. https://doi.org/10.1016/j.tra.2003.10.002

[32] Niu, B. and Zhang, J. (2013) Price, Capacity and Concession Period Decisions of Pareto-Efficient BOT Contracts with Demand Uncertainty. Transportation Research Part E: Logistics \& Transportation Review, 53, 1-14. https://doi.org/10.1016/j.tre.2013.01.012

[33] Scandizzo, P.L. and Venturab, M. (2010) Sharing Risk through Concession Contracts. European Journal of Operational Research, 207, 363-370. https://doi.org/10.1016/j.ejor.2010.04.008

[34] Carbonara, N., Pellegrino, R., Carbonara, N. and Pellegrino, R. (2018) Public-Private Partnerships for Energy Efficiency Projects: A Win-Win Model to Choose the Energy Performance Contracting Structure. Journal of Cleaner Production, 170, 1064-1075. https://doi.org/10.1016/j.jclepro.2017.09.151

[35] Xu, H. and Li, Q. (2010) The Game Theory Analysis of Risk Share for PPP Project Based on Shapley Value. 2010 2nd IEEE International Conference on Information Management and Engineering, Chengdu, 16-18 April 2010, 112-115. https://doi.org/10.1109/icime.2010.5477813

[36] Burke, R. and Demirag, I. (2016) Risk Transfer and Stakeholder Relationships in Public Private Partnerships. Accounting Forum, 41, 28-43. https://doi.org/10.1016/j.accfor.2016.06.004

[37] Saussier, S. (2000) Transaction Costs and Contractual Incompleteness: The Case of Électricité de France. Journal of Economic Behavior \& Organization, 42, 189-206. https://doi.org/10.1016/s0167-2681(00)00085-8

[38] Lahdenpera, P. (2010), Conceptualizing a Two-Stage Target-Cost Arrangement for Competitive Cooperation. Construction Management and Economics, 28, 783-796. https://doi.org/10.1080/01446193.2010.487534

[39] Feng, Z., Zhang, S.B. and Gao, Y. (2014) On Oil Investment and Production: A Comparison of Production Sharing Contracts and Buyback Contracts. Energy Economics, 42, 395-402. https://doi.org/10.1016/j.eneco.2014.01.010

[40] Sheu, J.B. (2011) Marketing-Driven Channel Coordination with Revenue-Sharing Contracts under Price Promotion to End-Customers. European Journal of Operational Research, 214, 246-255. https://doi.org/10.1016/j.ejor.2011.04.031

[41] Lippman, S.A., Mccardle, K.F. and Tang, C.S. (2013) Using Nash Bargaining to Design Project Management Contracts under Cost Uncertainty. International Journal of Production Economics, 145, 199-207. https://doi.org/10.1016/j.ijpe.2013.04.036

[42] Shang, T., Zhang, K., Liu, P., Chen, Z., Li, X. and Wu, X. (2015) What to Allocate and How to Allocate?-Benefit Allocation in Shared Savings Energy Performance Contracting Projects. Energy, 91, 60-71. https://doi.org/10.1016/j.energy.2015.08.020

[43] Qiu, L.D. and Wang, S. (2011) BOT Projects: Incentives and Efficiency. Journal of Development Economics, 94, 127-138. https://doi.org/10.1016/j.jdeveco.2009.11.008

[44] Martimort, D. (2006) An Agency Perspective on the Costs and Benefits of Privatization. Journal of Regulatory Economics, 30, 5-44.

[45] Ministry of Finance of China No. 156 (2014) PPP Project Contract Guide (Trial) (in Chinese). http://www.cpppc.org/zh/bmwj/2670.jhtml

[46] Grimsey, D. and Lewis, M.K. (2002) Evaluating the Risks of Public Private Partnerships for Infrastructure Projects. International Journal of Project Management, 20, 107-118. https://doi.org/10.1016/s0263-7863(00)00040-5 